\title{
Waldiomycin, a novel WalK-histidine kinase inhibitor from Streptomyces sp. MK844-mF10
}

\author{
Masayuki Igarashi ${ }^{1}$, Takafumi Watanabe ${ }^{2}$, Tomohiro Hashida ${ }^{1}$, Maya Umekita ${ }^{1}$, Masaki Hatano ${ }^{1}$, \\ Yohei Yanagida $^{2}$, Hirokazu Kino ${ }^{2}$, Tomoyuki Kimura ${ }^{1}$, Naoko Kinoshita $^{1}$, Kunio Inoue ${ }^{1}$, Ryuichi Sawa ${ }^{1}$, \\ Yoshio Nishimura ${ }^{1}$, Ryutaro Utsumi ${ }^{2}$ and Akio Nomoto ${ }^{1}$
}

WalK, a histidine kinase, and WaIR, a response regulator, make up a two-component signal transduction system that is indispensable for the cell-wall metabolism of low GC Gram-positive bacteria. WalK inhibitors are likely to show bactericidal effects against methicillin-resistant Staphylococcus aureus. We discovered a new WalK inhibitor, designated waldiomycin, by screening metabolites from actinomycetes. Waldiomycin belongs to the family of angucycline antibiotics and is structurally related to dioxamycin. Waldiomycin inhibits WalK from $S$. aureus and Bacillus subtilis at $\mathrm{IC}_{50} \mathrm{~S} 8.8$ and $10.2 \mu \mathrm{m}$, respectively, and shows antibacterial activity with MICs ranging from 4 to $8 \mu \mathrm{g} \mathrm{ml} \mathrm{m}^{-1}$ against methicillin-resistant $S$. aureus and $B$. subtilis. The Journal of Antibiotics (2013) 66, 459-464; doi:10.1038/ja.2013.33; published online 1 May 2013

Keywords: angucycline antibiotics; two-component signal transduction systems; histidine kinase inhibitor; Streptomyces sp.; WalK/WalR

\section{INTRODUCTION}

Two-component signal transduction systems (TCSs) allow bacteria to rapidly adapt to physical, chemical and biological stresses from outside the cell. The bacterial TCS consists of a membrane-bound sensor histidine kinase $(\mathrm{HK})$ and a cytosolic response regulator (RR). ${ }^{1}$ In response to an environmental signal, the sensor HK autophosphorylates a conserved histidine residue in the dimerization domain and transfers the phosphoryl group to the conserved aspartic acid in the regulatory domain of its cognate RR. The phosphorylated RR then binds to the upstream promoter regions of target genes to regulate their expression. Some TCSs that control gene clusters are essential for cell viability, whereas others control genes involved in virulence, biofilm formation and quorum sensing in pathogenic bacteria. ${ }^{2}$ Thus, TCS inhibitors are expected to exert a range of effects on cell viability. $^{2,3}$ The WalK/WalR TCS is essential for survival and is specific to low GC-content Gram-positive bacteria such as Bacillus subtilis, ${ }^{4}$ Staphylococcus aureus ${ }^{5}$ and Enterococcus faecalis, ${ }^{6}$ and is attracting increasing attention as a novel antibacterial drug target. $^{2,7,8}$ WalK is a membrane-linked $\mathrm{HK}$ that possesses two domains at the cytoplasmic C-terminal region: a catalytic (kinase or ATP-binding) domain and a dimerization domain containing a conserved phosphorylated histidine residue (H386 of B. subtilis). ${ }^{9}$ Six WalK inhibitors were found using structure-based virtual screening of chemical molecules by targeting the ATP-binding domain. ${ }^{10}$ We previously reported the development of a sensitive differential growth assay to screen for WalK inhibitors from natural sources. ${ }^{11}$ Using this screening method, we isolated two new antibiotics, signermycin $\mathrm{B}^{12}$ and walkmycins. ${ }^{13}$ Signermycin $\mathrm{B}$ inhibits autophosphorylation by binding to the WalK-dimerization domain and thereby hindering WalK/WalR signal transduction involved in cell growth and division. These results suggest that both the dimerization domain and the ATP-binding domain of WalK should be promising targets for developing antibiotics active against drug-resistant bacteria. Therefore, we screened metabolites from actinomycetes to isolate $\mathrm{HK}$ inhibitors using a differential growth assay with transformed B. subtilis, ${ }^{11}$ focusing on the discovery of a new antibiotic.

In this paper, we describe the isolation, structure determination and biological activity of a new HK inhibitor, designated waldiomycin, produced by Streptomyces sp. MK844-mF10 (Figures 1a and b).

\section{RESULTS AND DISCUSSION}

Taxonomy of the antibiotic-producing strain

Waldiomycin-producing organism, strain MK844-mF10, was isolated from a soil sample collected at Shiogama, Miyagi, Japan. Strain MK844-mF10 formed well-branched substrate mycelia. This strain also formed straight to flexuous aerial mycelia (Figure 1b). The aerial mycelia were brownish white. The whole-cell hydrolysates of the strain contained L,L-diaminopimelic acid. The partial $16 \mathrm{~S}$ ribosomal RNA gene sequence ( $1480 \mathrm{bp}$ ) was determined and deposited in the DNA Data Bank of Japan with the accession number AB738076. The strain showed high similarity to strains of the genus Streptomyces, such as 
a

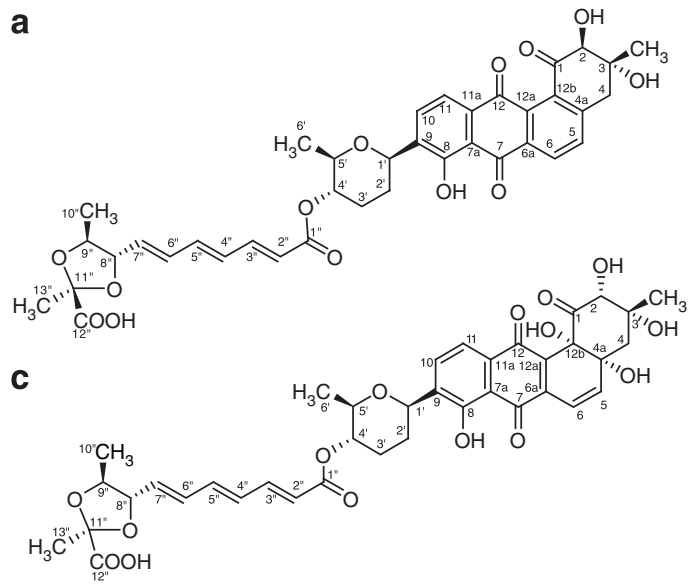

b

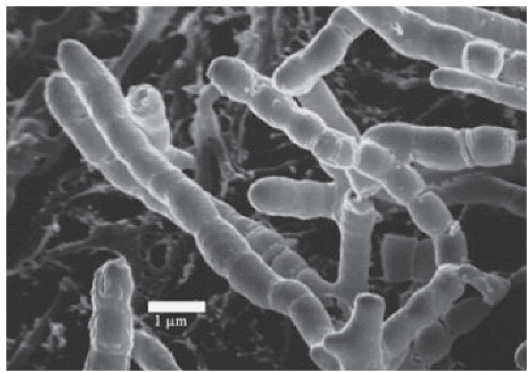

Figure 1 (a) Structure of waldiomycin. (b) Streptomyces sp. MK844-mF10. (c) Structure of dioxamycin.

Streptomyces yeochonensis CN $732^{\mathrm{T}} \quad(1451 / 1473 \mathrm{bp}, \quad 98.5 \%)$, S. paucisporeus $1413^{\mathrm{T}}(1430 / 1447 \mathrm{bp}, 98.8 \%)$ and S. hebeiensis YIM $001^{\mathrm{T}}$ (1447/1482 bp, 97.6\%). These phenotypic and genotypic data suggested that the strain MK844-mF10 belongs to the genus Streptomyces. Therefore, the strain was tentatively designated as Streptomyces sp. MK844-mF10.

\section{Fermentation and isolation of waldiomycin}

Streptomyces sp. MK844-mF10 was inoculated into a 500-ml baffled Erlenmeyer flask containing $110 \mathrm{ml}$ of seed medium. The seed culture was incubated in a rotary shaker $\left(180\right.$ r.p.m.) at $30^{\circ} \mathrm{C}$ for 2 days. Waldiomycin was produced by solid-state culture. Seed culture $(7 \mathrm{ml})$ was transferred into a $500-\mathrm{ml} \mathrm{K}-1$ flask containing $40 \mathrm{~g}$ of a producing medium. The fermentation was carried out at $30^{\circ} \mathrm{C}$ for 14 days in the dark. The production of waldiomycin reached $103 \mathrm{mg} \mathrm{kg}^{-1}$ of culture. The fermentation material $(2360 \mathrm{~g})$ was extracted with an equal amount of EtOH. The EtOH extract containing waldiomycin was adsorbed onto reversed-phase CHP-20P polymers and eluted with acetone. The concentrated acetone eluate was washed with hexane to leave nonpolar material and give $2.89 \mathrm{~g}$ of crude material. The material was chromatographed on an LH20 column and eluted with $\mathrm{MeOH}$. The active fractions were collected and further purified by reverse-phase HPLC to give $110.5 \mathrm{mg}$ of waldiomycin.

\section{Structure determination of waldiomycin}

Waldiomycin was obtained as a yellow plate crystal (m.p. $167-172{ }^{\circ} \mathrm{C}$, dec.), with optical rotation parameters of $[\alpha]_{\mathrm{D}}^{27}+114.3^{\circ}$ (c 0.1 , $\mathrm{MeOH})$. The UV spectral data of waldiomycin were: UV $\lambda_{\max }(\varepsilon) 275$ (42 700), 292 (41 800), 305 (3500) and $406(5700)$ in $0.005 \mathrm{M} \mathrm{HCl}-$ $\mathrm{MeOH}$; 277 (36000), 295 (38700), 308 (3400) and 509 (4800) in $0.005 \mathrm{~m} \mathrm{NaOH}-\mathrm{MeOH}$. The IR spectral data were: $v_{\max }(\mathrm{KBr}) \mathrm{cm}^{-1}$ $3700-3200,2929,1710,1675,1631,1592,1274,1124$ and 1078. The UV spectrum of waldiomycin showed a bathochromic shift in alkaline conditions, suggesting the presence of a phenolic naphthoquinone chromophore.

The molecular formula of waldiomycin was determined as $\mathrm{C}_{38} \mathrm{H}_{38} \mathrm{O}_{13}$, based on high-resolution ESI MS (HRESI-MS), which gave a $(\mathrm{M}+\mathrm{H})^{+}$ion at $m / z 703.2394(\Delta+0.92 \mathrm{mDa}$; calculated for $\mathrm{C}_{38} \mathrm{H}_{39} \mathrm{O}_{13}$ ), and the NMR data. The ${ }^{1} \mathrm{H}$ and ${ }^{13} \mathrm{C}$ NMR spectral data of waldiomycin are summarized in Table 1. The DEPT and HMQC spectra of waldiomycin revealed four methyl groups, three methylene groups, sixteen methine groups, eight olefinic quaternary carbons,
Table $1{ }^{1} \mathrm{H}$ and ${ }^{13} \mathrm{C}$ NMR data of waldiomycin in $\mathrm{CDCl}_{3}$

\begin{tabular}{|c|c|c|c|c|c|c|c|c|c|}
\hline Position & $\delta_{C}$ & $\delta_{H}$ & & $\mathrm{~J}$ in $\mathrm{Hz}$ & Position & $\delta_{C}$ & $\delta_{H}$ & & $\mathrm{~J}$ in $\mathrm{Hz}$ \\
\hline 1 & 197.2 & & & & $1^{\prime}$ & 73.3 & 4.88 & $\mathrm{dd}$ & $10.2,1.3$ \\
\hline 2 & 82.0 & 4.86 & $\mathrm{~s}$ & & $2^{\prime}$ & 31.4 & 1.55 & $\mathrm{~m}$ & \\
\hline 3 & 77.0 & & & & & & 2.26 & $\mathrm{~m}$ & \\
\hline \multirow[t]{2}{*}{4} & 42.8 & 3.29 & $d$ & 17.1 & $3^{\prime}$ & 29.7 & 1.76 & $\mathrm{~m}$ & \\
\hline & & 3.45 & $d$ & 17.1 & & & 2.28 & $\mathrm{~m}$ & \\
\hline $4 a$ & 147.1 & & & & $4^{\prime}$ & 73.4 & 4.67 & ddd & $4.4,9.7,11.5$ \\
\hline 5 & 134.0 & 7.64 & d & 7.9 & $5^{\prime}$ & 76.3 & 3.70 & $\mathrm{dq}$ & $6.0,9.7$ \\
\hline 6 & 130.5 & 8.40 & $d$ & 7.9 & $6^{\prime}$ & 18.4 & 1.29 & $d$ & 6.0 \\
\hline $6 a$ & 132.5 & & & & $1^{\prime \prime}$ & 166.1 & & & \\
\hline 7 & 187.4 & & & & $2^{\prime \prime}$ & 122.1 & 5.95 & $d$ & 15.2 \\
\hline $7 a$ & 114.6 & & & & $3^{\prime \prime}$ & 144.1 & 7.32 & $\mathrm{dd}$ & $10.5,15.2$ \\
\hline 8 & 158.5 & & & & $4^{\prime \prime}$ & 131.7 & 6.39 & $\mathrm{dd}$ & $10.5,15.9$ \\
\hline 9 & 138.8 & & & & $5^{\prime \prime}$ & 138.8 & 6.58 & $\mathrm{dd}$ & $10.2,15.9$ \\
\hline 10 & 134.0 & 7.95 & d & 7.6 & $6^{\prime \prime}$ & 133.9 & 6.47 & $\mathrm{dd}$ & $10.2,15.2$ \\
\hline 11 & 119.9 & 7.73 & $d$ & 7.6 & $7^{\prime \prime}$ & 131.2 & 5.83 & $\mathrm{dd}$ & $15.2,8.5$ \\
\hline $11 \mathrm{a}$ & 133.5 & & & & $8^{\prime \prime}$ & 84.6 & 4.26 & $\mathrm{dd}$ & $8.5,9.5$ \\
\hline 12 & 182.3 & & & & $9^{\prime \prime}$ & 78.3 & 3.90 & $\mathrm{dq}$ & $6.0,9.5$ \\
\hline $12 a$ & 137.3 & & & & $10^{\prime \prime}$ & 16.4 & 1.34 & $d$ & 6.0 \\
\hline $12 b$ & 134.0 & & & & $11^{\prime \prime}$ & 104.8 & & & \\
\hline \multirow[t]{2}{*}{ 3-Me } & 20.4 & 1.07 & $\mathrm{~s}$ & & $12^{\prime \prime}$ & 171.5 & & & \\
\hline & & & & & $13^{\prime \prime}$ & 22.9 & 1.66 & $\mathrm{~s}$ & \\
\hline
\end{tabular}

two $\mathrm{sp}^{3}$ quaternary carbons attached to oxygen and five carbonyl carbons. The sixteen methine groups were presumed to be six olefinic, four aromatic and six sp $\mathrm{sp}^{3}$. The ${ }^{1} \mathrm{H}$ and ${ }^{13} \mathrm{C} \mathrm{NMR}$ data of waldiomycin were similar to those of dioxamycin except for signals assigned to the angucyclinone portion.

The ${ }^{1} \mathrm{H}-{ }^{1} \mathrm{H}$ COSY and HMBC spectra suggested that waldiomycin contained four partial structures $(\mathbf{a}, \mathbf{b}, \mathbf{c}$ and $\mathbf{d})$, as shown in Figure 2. The ${ }^{13} \mathrm{C}-{ }^{1} \mathrm{H}$ couplings of ${ }^{2} \mathrm{~J}$ and ${ }^{3} \mathrm{~J}$ observed in the HMBC experiments gave the following results. The cross peaks from $\delta 4.86(2-\mathrm{H})$ to $\delta 197.2(\mathrm{C}-1), \delta 77.0(\mathrm{C}-3)$ and $\delta 134.0(\mathrm{C}-12 \mathrm{~b})$, from $\delta 1.07\left(3-\mathrm{CH}_{3}\right)$ to $\delta 82.0(\mathrm{C}-2), \delta 77.0(\mathrm{C}-3)$ and $\delta 42.8(\mathrm{C}-4)$, from $\delta 7.64(5-\mathrm{H})$ to $\delta$ $42.8(\mathrm{C}-4), \delta 147.1(\mathrm{C}-4 \mathrm{a})$ and $\delta 134.0(\mathrm{C}-12 \mathrm{~b})$, from $\delta 8.40(6-\mathrm{H})$ to $\delta 132.5$ (C-6a), $\delta 187.4(\mathrm{C}-7)$ and $\delta 137.3(\mathrm{C}-12 \mathrm{a})$, from $\delta 7.95$ $(10-\mathrm{H})$ to $\delta 158.5(\mathrm{C}-8)$ and $\delta 133.5(\mathrm{C}-11 \mathrm{a})$, and from $\delta 7.73(11-\mathrm{H})$ to $\delta 114.6$ (C-7a), 138.8 (C-9) and $\delta 182.3$ (C-12) supported the partial structure a. The cross peaks from $\delta 4.88\left(1^{\prime}-\mathrm{H}\right)$ to $\delta 76.3\left(\mathrm{C}-5^{\prime}\right)$ and from $\delta 4.88\left(5^{\prime}-\mathrm{H}\right)$ to $\delta 73.3\left(\mathrm{C}-1^{\prime}\right)$, and the cross peak from 
a

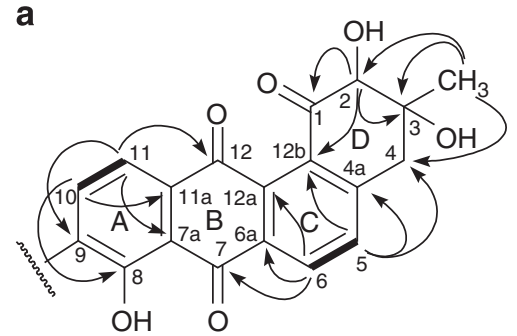

C

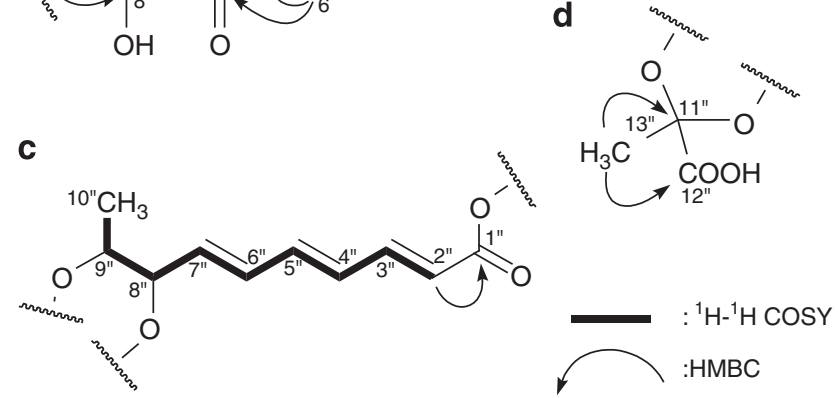

b

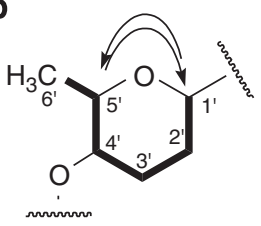

Figure 2 Partial structures of waldiomycin and its COSY and HMBC results.

$\delta 5.95\left(2^{\prime \prime}-\mathrm{H}\right)$ to $\delta 166.1\left(\mathrm{C}-1^{\prime \prime}\right)$ supported the partial structure $\mathbf{b}$ and the partial structure $\mathbf{c}$, respectively. The cross peaks from $\delta 1.66\left(13^{\prime \prime}-\right.$ $\mathrm{H})$ to $104.8\left(\mathrm{C}-11^{\prime \prime}\right)$ and $171.5\left(\mathrm{C}-12^{\prime \prime}\right)$ supported the partial structure $\mathbf{d}$. The connectivity of the partial structures a-d was established by analyses of HMBC and NOE. The anomeric proton at $\delta 4.88\left(1^{\prime}-\mathrm{H}\right)$ in sugar moiety (b) showed HMBC correlation with the aromatic carbon at $\delta 158.5(\mathrm{C}-8), \delta 138.8(\mathrm{C}-9)$ and $\delta 134.0(\mathrm{C}-$ 10) in chromophore moiety (a), thus establishing the connectivity of anomeric carbon to C-9. The methine proton bearing an oxygen atom at $\delta 4.67\left(4^{\prime}-\mathrm{H}\right)$ in sugar moiety (b) exhibited HMBC correlation to the carbonyl carbon at $\delta 166.1\left(\mathrm{C}-1^{\prime \prime}\right)$ in trienone moiety and confirmed esterification of oxygen at $4^{\prime}$.

An NOE was observed between the methine proton bearing an oxygen atom at $\delta 3.90\left(9^{\prime \prime}-\mathrm{H}\right)$ and the methyl proton at $\delta 1.66\left(13^{\prime \prime}\right.$ $\mathrm{H})$, establishing the connectivity of the partial structures $\mathbf{c}$ and $\mathbf{d}$. The above observaton of NOE experiment while structure was established, why there was no HMBC correlation has been observed/reported from $\mathrm{H}-8^{\prime \prime}$ and $\mathrm{H}-9^{\prime \prime}$ to $\mathrm{C}-11^{\prime \prime}$, the planar structure of waldiomycin was elucidated as shown in Figure 3 a.

The relative configuration of waldiomycin was determined by X-ray crystallography. Crystallization of waldiomycin from aqueous acetonitrile produced yellow platelet crystals suitable for X-ray structure analysis. The X-ray structure analysis data have been deposited at the Cambridge Crystallographic Data Centre and allocated the deposition number CCDC 892997. The ORTEP drawing of waldiomycin is shown in Figure 3b. Waldiomycin is a new natural product from an actinomycete and possesses an angucycline chomophore with 4-((1E,3E,5E)-6-carboxyhexa-1,3,5-trien-1-yl)-2,5-dimethyl-1,3-dioxolane-2-carboxylic acid, and is closely related to dioxamycin, ${ }^{14}$ except for the junction of the C-D ring and the stereochemistry of C-2 at D ring. Detailed absolute stereochemical studies of waldiomycin are now in progress.

\section{Biological activity of waldiomycin}

Antimicrobial activity. We evaluated the antimicrobial activity of waldiomycin against Gram-positive and -negative bacteria. The antimicrobial activities of waldiomycin are shown in Table 2. Waldiomycin exhibited moderate antimicrobial activity against Gram-positive bacteria except for E. faecalis and no antibacterial activity against Mycobacterium smegmatis and Gram-negative bacteria.

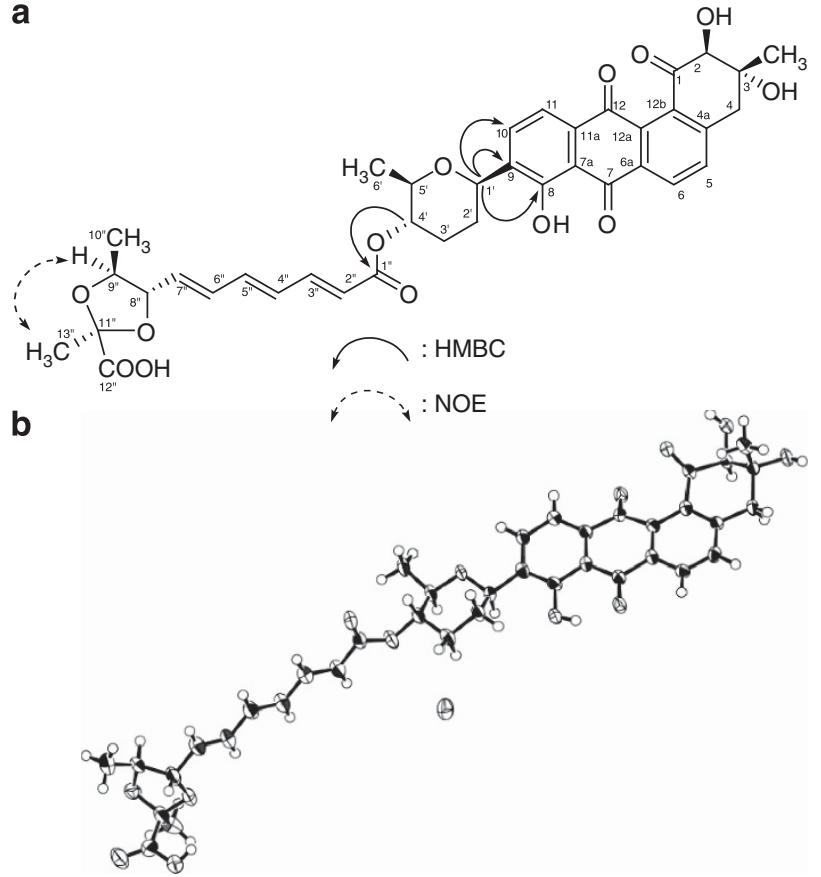

Figure 3 (a) Key HMBC and NOE correlations of waldiomycin. (b) ORTEP drawing of waldiomycin.

Table 2 Antimicrobial activities of waldiomycin and its methyl ester

\begin{tabular}{|c|c|c|c|}
\hline \multirow[b]{2}{*}{ Organisms } & \multirow[b]{2}{*}{ Strain } & \multicolumn{2}{|c|}{$M I C\left(\mu g m I^{-1}\right)$} \\
\hline & & Waldiomycin & $\begin{array}{c}\text { Waldiomycin } \\
\text { Me ester }\end{array}$ \\
\hline Staphylococcus aureus & FDA209P & 8 & 64 \\
\hline S. aureus & Smith & 8 & 64 \\
\hline S. aureus & MS9610 & 16 & 64 \\
\hline S. aureus & MS16526(MRSA) & 16 & 64 \\
\hline S. aureus & TY-04282(MRSA) & 16 & 64 \\
\hline Micrococcus luteus & IF03333 & 8 & $>64$ \\
\hline M. luteus & PCI1001 & 16 & $>64$ \\
\hline Bacillus subtilis & & 8 & 64 \\
\hline Enterococcus faecalis & ATCC10702 & 128 & $>64$ \\
\hline E. faecalis & 1810 & 128 & $>64$ \\
\hline Escherichia coli & $\mathrm{K}-12$ & $>128$ & $>64$ \\
\hline Shigella dysenteriae & JS11910 & $>128$ & $>64$ \\
\hline Salmonella enteritidis & 1891 & $>128$ & $>64$ \\
\hline Mycobacterium & ATCC607 & $>128$ & $>64$ \\
\hline smegmatis & & & \\
\hline Candida albicans & 3147 & $>128$ & $>64$ \\
\hline
\end{tabular}

Abbreviation: MRSA, methicillin-resistant $S$. aureus.

$H K$ inhibitory activity. We examined the inhibitory activity of waldiomycin for WalK autophosphoryation in vitro. As shown in Figure 4a, the bands for the autophosphorylated WalK (Bs) and WalK (Sa) clearly disappeared in a dose-dependent manner. Waldiomycin completely inhibited the incorporation of labeled phosphate from $\left[\gamma^{32} \mathrm{P}\right]$ ATP into $\mathrm{WalK}(\mathrm{Sa})$ and $\mathrm{WalK}(\mathrm{Bs})$ at 22 and $45 \mu \mathrm{M}$, respectively, and the $\mathrm{IC}_{50}$ values were 8.8 and $10.2 \mu \mathrm{M}$, respectively. We also studied the HK inhibitory activity against WalK (Bs) using waldiomycin methyl ester and the related angucyclinone antibiotics aquayamycin, ${ }^{15}$ rabelomycin ${ }^{16}$ and sakyomicin A. ${ }^{17}$ Aquayamycin, 


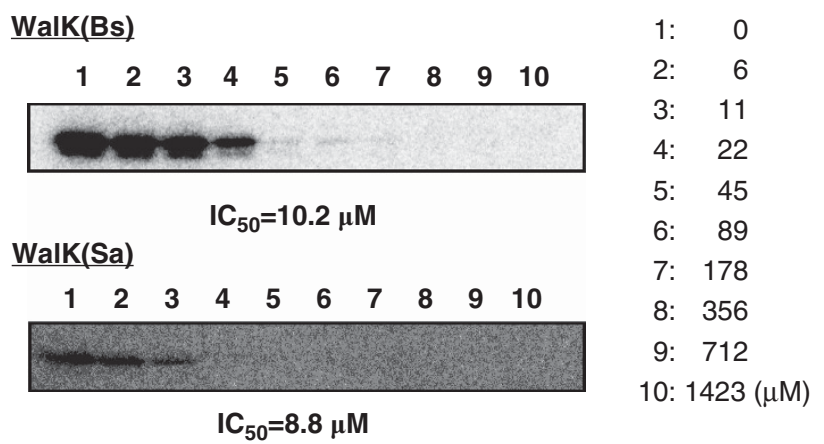

\section{b $1 \begin{array}{llllllllll}1 & 2 & 3 & 4 & 5 & 6 & 7 & 8 & 9 & 10\end{array}$ vs waldiomycin Me ester}

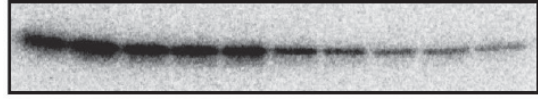

vs aquayamycin

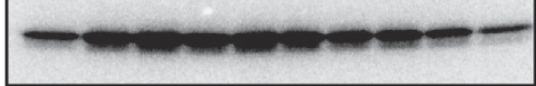

vs rabelomycin

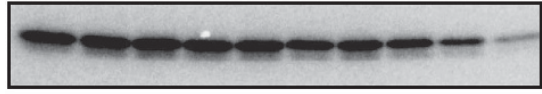

vs sakyomicin A

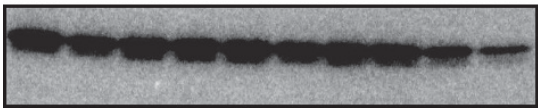

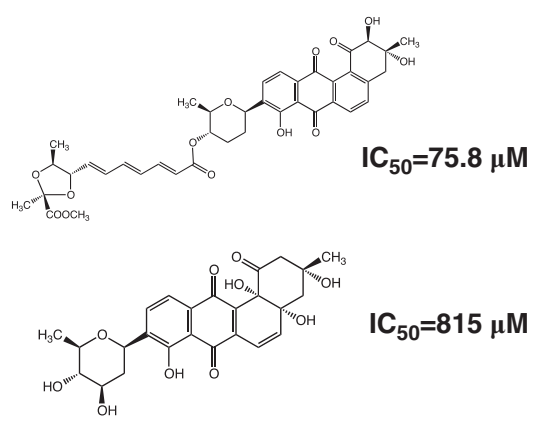

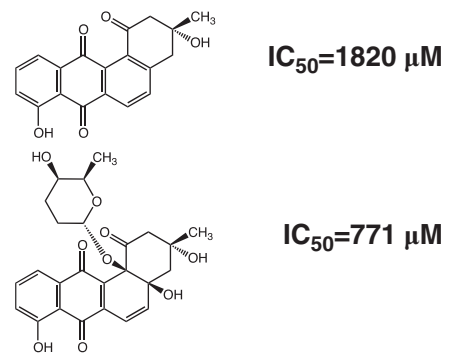

Figure 4 (a) Inhibition of autophosphorylation of WalK (Bs) and WalK (Sa) with waldiomycin. (b) HK inhibitory activities of the angucyclinone antibiotics aquayamycin, rabelomycin and sakyomicin $\mathrm{A}$ against WalK (Bs). IC $\mathrm{C}_{50}$ was measured as described in Methods.

rabelomycin and sakyomicin A displayed minimal inhibition of WalK (Bs) activity, as shown in Figure $4 \mathrm{~b}$.

Angucyclinone antibiotics such as aquayamycin, rabelomycin and sakyomicin A have been reported as microbial metabolites. They show antimicrobial activity as the same range of MIC (for example, waldiomycin $\left(8 \mu \mathrm{g} \mathrm{ml}^{-1}\right)$, aquayamycin $\left(3.13 \mu \mathrm{g} \mathrm{ml}^{-1}\right),{ }^{15}$ rabelomycin $\left(6.3 \mu \mathrm{g} \mathrm{ml}^{-1}\right)^{16}$ and sakyomicin A $\left(9.38 \mu \mathrm{g} \mathrm{ml}^{-1}\right)$ against S. aureus). ${ }^{17}$ However, these compounds showed no inhibitory activity against $\mathrm{HK}$ and no positive response in the differential growth assay. Moreover, a methyl ester at C-12" of waldiomycin carboxylic acid has no activity against either $\mathrm{HK}$ or Gram-positive bacteria (Figure $4 \mathrm{~b}$ and Table 2). Simocyclinones, ${ }^{18}$ a group of antibiotics related to waldiomycin, are bifunctional antibiotics that inhibit bacterial DNA gyrase. It has been revealed that the aminocumarin and angucyclin moieties in simocyclinone are indispensable for potent inhibitory activity by interacting independently to the binding pocket of DNA gyrase. Thus, the dioxolan carboxylic acid and angucycline moieties in waldiomycin may be important for HK inhibitory activity. Detailed studies on the HK inhibitory activity, kinetics, control of transcription of essential genes and structure-activity relationships of waldiomycin are in progress.

\section{METHODS}

\section{General experimental procedures}

The optical rotation of the isolated waldiomycin was measured with a P-1030 polarimeter (JASCO, Tokyo, Japan). UV spectra were recorded with a U-2800 spectrophotometer (Hitachi High-Technologies, Tokyo, Japan). IR spectra were recorded with a FT-210 Fourier transform infrared spectrometer (Horiba, Kyoto, Japan). The ${ }^{1} \mathrm{H}$ and ${ }^{13} \mathrm{C}$ NMR spectra were measured with a JNMECA600 spectrometer (JEOL, Tokyo, Japan) at $25^{\circ} \mathrm{C}$ using tetramethylsilane as an internal reference. The mass spectrum was recorded with a LTQ Orbitrap XL mass spectrometer (Thermo Fisher Scientific, San Jose, CA, USA).

\section{Differential growth assay}

Wild-type parental strains 168 and CNM2000 were cultured overnight in 3\% Trypticase soy broth (Becton Dickinson, Franklin Lakes, NJ, USA). Then, $30 \mu \mathrm{l}$ of the overnight culture was added to $3 \mathrm{ml}$ of top agar (0.75\% Trypticase Soy broth, $1.5 \%$ agar), dissolved at $55^{\circ} \mathrm{C}$, and the mixture was poured into a $10-\mathrm{ml}$ bottom agar plate ( $0.75 \%$ Trypticase Soy broth, $0.5 \%$ agar). Once cool, $1 \mu \mathrm{l}$ of the screen sample was spotted. Following overnight culture at $37^{\circ} \mathrm{C}$, halos were observed in the 168 plate and the CNM 2000 plate.

\section{Inhibition of WalK autophosphorylation}

WalK solution $\left(2 \mu \mathrm{l}\right.$ of $2.5 \mathrm{pmol} \mu \mathrm{l}^{-1}$ WalK (Bs: B. subtilis 168 amino acids $207-611)^{13}$ and WalK (Sa: S. aureus N315 amino acids $\left.235-608\right)^{13}$ and $5 \mu$ l of 
kinase buffer ( $50 \mathrm{~mm}$ Tris- $\mathrm{HCl}(\mathrm{pH} 8.5), 100 \mathrm{~mm} \mathrm{KCl,} 100 \mathrm{~mm} \mathrm{NH}_{4} \mathrm{Cl}, 5 \mathrm{~mm}$ $\mathrm{MgCl}_{2}$ ) were mixed. Then, $1 \mu \mathrm{l}$ of drug solution was added to the mixture. After $5 \mathrm{~min}, 2 \mu \mathrm{l}$ of $12.5 \mu \mathrm{M}$ ATP solution $\left(2.5 \mu \mathrm{M}\right.$ ATP and $16.7 \mathrm{~nm}\left[\gamma_{-}{ }^{32} \mathrm{P}\right]$ ATP $)$ was added to the mixture for autophosphorylation. The reaction was stopped 10 min later using SDS sample buffer (300 mm Tris- $\mathrm{HCl}(\mathrm{pH} 8.0), 10 \%(\mathrm{w} / \mathrm{v})$ SDS, 25\% (v/v) $\beta$-mercaptoethanol, 50\% (v/v) glycerol, 0.25\% (w/v) bromophenol blue), and SDS-polyacrylamide gel electrophoresis was performed. Following drying, the gel was exposed to an imaging plate. Signal bands were detected by FLA-7000 (Fujifilm, Tokyo, Japan) using the Multi Gauge Version 3.0 (Fujifilm) analytical software, and Prism 5 (GraphPad Software, La Jolla, CA, USA) was used to calculate the $\mathrm{IC}_{50}$

\section{Taxonomic studies of the producing strain MK844-mF10}

Morphological properties were observed following incubation at $30^{\circ} \mathrm{C}$ for 21 days on yeast extract-malt extract agar (ISP medium no. 2), oatmeal agar (ISP medium no. 3) and inorganic salts-starch agar (ISP medium no. 4). Detailed observation of mycelial morphology was performed using a scanning electron microscope S-570 (Hitachi High-Technologies) after the strain MK844-mF10 was incubated on ISP medium no. 3 at $30^{\circ} \mathrm{C}$ for 14 days. The type of diaminopimelic acid isomers in whole-cell hydrolysates was determined by the method of Staneck and Roberts. ${ }^{19}$ Total DNA of MK844-mF10 was prepared using a Genomic DNA Extraction Kit Mini (RBC Bioscience Co., New Taipei, Taiwan) according to manufacturer's instructions. 16S rRNA (positions 311524, Escherichia coli numbering system $)^{20}$ was amplified by PCR and sequenced. A search for the most closely related sequences was performed using the BLAST algorithm at the DNA Data Bank of Japan.

\section{Fermentation of waldiomycin}

A slant culture of MK844-mF10 was inoculated into a 500-ml baffled Erlenmeyer flask containing $110 \mathrm{ml}$ of a seed medium consisting of $2 \%$ $(\mathrm{w} / \mathrm{v})$ galactose, 2\%(w/v) dextrin, 1\%(w/v) Bacto-soytone (Becton Dickinson), $0.5 \%(\mathrm{w} / \mathrm{v})$ corn steep liquor (Kogo Starch, Chiba, Japan), 1\% (w/v) glycerol, $0.2 \%(\mathrm{w} / \mathrm{v})\left(\mathrm{NH}_{4}\right)_{2} \mathrm{SO}_{4}$ and $0.2 \%(\mathrm{w} / \mathrm{v}) \mathrm{CaCO}_{3}$ in deionized water ( $\mathrm{pH} 7.4$ before sterilization). The seed culture was incubated in a rotary shaker ( 180 r.p.m.) at $30^{\circ} \mathrm{C}$ for 2 days. The producing culture was generated by solidstate fermentation. Seed culture $(7 \mathrm{ml})$ was transferred into a $500-\mathrm{ml} \mathrm{K}-1$ flask containing $40 \mathrm{~g}$ of a producing medium consisting of pressed barley $15 \mathrm{~g}$ and deionized water $25 \mathrm{~g}$. The fermentation was carried out at $30^{\circ} \mathrm{C}$ for 14 days in the dark.

\section{Purification of waldiomycin}

The fermentation material $(2360 \mathrm{~g})$ was extracted with an equal amount of EtOH. The EtOH extract was added to 101 of deionized water and $700 \mathrm{ml}$ of Diaion CHP-20 P (Mitsubishi Chemical, Tokyo, Japan), and the mixture was stirred for $1 \mathrm{~h}$. After $18 \mathrm{~h}$, the Diaion CHP-20 P was collected by filtration and washed with $50 \% \mathrm{MeOH}(3500 \mathrm{ml})$. Active material was eluted with $100 \%$ acetone $(3500 \mathrm{ml})$. The acetone eluate was concentrated and washed with hexane to give $2.89 \mathrm{~g}$ of crude material. The material was chromatographed on a LH20 column $(32 \mathrm{~mm}$ i.d. $\times 600 \mathrm{~mm})$ and eluted with $\mathrm{MeOH}$. The active fractions were collected and further purified by reverse-phase HPLC, on a Capcell pak UG-120 column $(20 \mathrm{~mm}$ i.d. $\times 250 \mathrm{~mm}$, Shiseido, Tokyo, Japan $)$, eluted with $50 \%$ aqueous acetonitrile, at a flow rate of $8 \mathrm{mlmin}^{-1}$. Waldiomycin was eluted from 34 to $44 \mathrm{~min}$ and was concentrated in vacuo to give a yellow microcrystal $(110.5 \mathrm{mg})$.

\section{Preparation of waldiomycin methyl ester}

The methyl ester of waldiomycin was prepared as follows. Waldiomycin $(26.5 \mathrm{mg})$ was dissolved in $2 \mathrm{ml}$ of $\mathrm{MeOH}$, and trimethylsilyldiazomethane (Tokyo Chemical Industry, Tokyo, Japan) in hexane was added to the solution and allowed to stand for $60 \mathrm{~min}$ at room temperature. Acetic acid was added to the reaction mixture, which was concentrated in vacuo. The reaction mixture was purified by silica gel column chromatography eluted with $\mathrm{CHCl}_{3}-\mathrm{MeOH}$ to give $17.4 \mathrm{mg}$ of waldiomycin methyl ester. HRESI-MS of waldiomycin methyl ester in positive ion mode found a species at $m / z 717.2542(\mathrm{M}+\mathrm{H})^{+}$, consistent with a calculated value for $\mathrm{C}_{39} \mathrm{H}_{40} \mathrm{O}_{13}+\mathrm{H}$ of 717.2545. ${ }^{1} \mathrm{H}$ NMR $\left(600 \mathrm{MHz}, \mathrm{CDCl}_{3}\right): \delta 1.07(\mathrm{~s}, 3-\mathrm{Me}), 1.29\left(\mathrm{~d}, J=6.4, \mathrm{H}-6^{\prime}\right), 1.31$ (d, $J=6.4$,

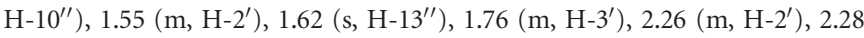
(m, H-3'), 3.29 (d, $J=17.0, \mathrm{H}-4), 3.44$ (d, $J=17.0, \mathrm{H}-4$ ), 3.71 (dq, $J=6.0,9.6$, H-5'), 3.79 (s, $12^{\prime \prime}-\mathrm{OMe}$ ), 3.86 (dq, $\left.J=6.0,9.5, \mathrm{H}-9^{\prime \prime}\right), 4.30$ (dd, $J=6.8,9.0$, H- ${ }^{\prime \prime}$ ), 4.66 (ddd, $\left.J=4.0,10.0,11.0, \mathrm{H}-4^{\prime}\right), 4.85$ (s, H-2), 4.88 (dd, $J=10.2$, 1.3, H-1' $), 5.85\left(\mathrm{dd}, J=6.8,15.0, \mathrm{H}-7^{\prime \prime}\right), 5.94\left(\mathrm{~d}, J=15.0, \mathrm{H}-2^{\prime \prime}\right)$, $6.38\left(\mathrm{dd}, J=11.0,15.0, \mathrm{H}-4^{\prime \prime}\right), 6.48\left(\mathrm{dd}, J=10.0,15.0, \mathrm{H}-6^{\prime \prime}\right), 6.58(\mathrm{dd}$, $\left.J=10.0,15.0, \mathrm{H}-5^{\prime \prime}\right), 7.32$ (dd, $\left.J=11.0,15.0, \mathrm{H}-3^{\prime \prime}\right), 7.63$ (d, $J=7.5, \mathrm{H}-5$ ), $7.73(\mathrm{~d}, J=7.4, \mathrm{H}-11), 7.94(\mathrm{~d}, J=7.4, \mathrm{H}-10)$ and 8.39 (d, $J=7.5, \mathrm{H}-6) ;{ }^{13} \mathrm{C}$ NMR $\left(150 \mathrm{MHz}, \mathrm{CDCl}_{3}\right) \delta 197.2(\mathrm{C}-1), 82.0(\mathrm{C}-2), 76.6$ (C-3), 42.8 (C-4), 147.1 (C-4a), 134.0 (C-5), 130.5 (C-6), 134.0 (C-6a), 187.4 (C-7), 114.6 (C7a), 158.5 (C-8), 138.0 (C-9), 134.0 (C-10), 119.3 (C-11), 133.5 (C-11a), 182.3 (C-12), 137.3 (C-12a), 132.5 (C-12b), $73.2\left(\mathrm{C}-1^{\prime}\right), 31.5\left(\mathrm{C}-2^{\prime}\right), 29.7\left(\mathrm{C}-3^{\prime}\right), 73.3$ $\left(\mathrm{C}-4^{\prime}\right), \quad 76.3\left(\mathrm{C}-5^{\prime}\right), \quad 18.4 \quad\left(\mathrm{C}-6^{\prime}\right), 166.1 \quad\left(\mathrm{C}-1^{\prime \prime}\right), 121.9 \quad\left(\mathrm{C}-2^{\prime \prime}\right), \quad 144.2$ $\left(\mathrm{C}-3^{\prime \prime}\right), 131.4\left(\mathrm{C}-4^{\prime \prime}\right), 139.0\left(\mathrm{C}-5^{\prime \prime}\right), 133.6\left(\mathrm{C}-6^{\prime \prime}\right), 131.8\left(\mathrm{C}-7^{\prime \prime}\right), 84.5$ $\left(\mathrm{C}-8^{\prime \prime}\right), 78.0\left(\mathrm{C}-9^{\prime \prime}\right), 16.4\left(\mathrm{C}-10^{\prime \prime}\right), 105.1\left(\mathrm{C}-11^{\prime \prime}\right), 170.7\left(\mathrm{C}-12^{\prime \prime}\right), 23.1$ $\left(\mathrm{C}-13^{\prime \prime}\right), 52.6\left(12^{\prime \prime}-\mathrm{OMe}\right)$ and $20.4(3-\mathrm{Me})$.

\section{$\mathrm{X}$-ray structure analysis}

Single-crystal X-ray data were collected on a Rigaku VariMax with a RAPID imaging plate area detector by graphite-monochromated $\mathrm{Cu}-\mathrm{K} \alpha$ radiation (Rigaku Company, Tokyo, Japan). Data collection was conducted at $93 \mathrm{~K}$ for waldiomycin. The structure was analyzed by direct methods in SIR2008, ${ }^{21}$ and refined using full-matrix least-squares in SHELXL97.22 All non-hydrogen atoms were refined anisotropically. All hydrogen atoms were placed in standard calculated positions and were refined isotropically. The final cycle of full-matrix least-squares refinement on $\mathrm{F}$ was based on 6386 observed reflections and 469 variable parameters, and converged with unweighted agreement factors of $R 1=0.0360$ and $w R 2=0.0978$.

\section{Antimicrobial activity}

MICs were determined by the standard agar dilution method recommended by the Clinical Laboratory Standards Institute (CLSI) guidelines. ${ }^{23}$ Bacteria were incubated on Mueller-Hinton agar (Becton Dickinson) at $37^{\circ} \mathrm{C}$ for $18 \mathrm{~h}$, while yeast was incubated for $42 \mathrm{~h}$.

\section{ACKNOWLEDGEMENTS}

This work was supported by the Research and Development Program for New Bio-Industry Initiatives (2006-2010) of the Bio-Oriented Technology Research Advancement Institution (BRAIN). We thank Ms Y Kubota, Ms R Arisaka, Ms $\mathrm{R}$ Nagasaka and T Suzuki for providing technical assistance.

1 Gao, R. \& Stock, A.M. Biological insights from structures of two-component proteins. Annu. Rev. Microbiol. 63, 133-154 (2009).

2 Gotoh, Y. et al. Two-component signal transduction as potential drug targets in pathogenic bacteria. Curr. Opin. Microbiol. 13, 232-239 (2010).

3 Cegelski, L, Marshall, G. R., Eldridge, G. R. \& Hultgren, S. J. The biology and future prospects of antivirulence therapies. Nat Rev Microbiol. 6, 17-27 (2008).

4 Fabret, C. \& Hoch, J. A. A two-component signal transduction system essential for growth of Bacillus subtilis: implications for anti-infective therapy. J. Bacteriol. 180, 6375-6383 (1998).

5 Martin, P. K., Li, T., Sun, D., Biek, D. P. \& Schmid, M. B. Role in cell permeability of an essential two-component system in Staphylococcus aureus. J. Bacteriol. 181, 3666-3673 (1999).

6 Hancock, L. \& Perego, M. Two-component signal transduction in Enterococcus faecalis. J. Bacteriol. 184, 5819-5825 (2002).

7 Schreiber, M., Res, I. \& Matter, A. Protein kinases as antibacterial targets. Curr. Opin. Cell. Biol. 21, 325-330 (2009).

8 Matsushita, M. \& Janda, K. D. Histidine kinases as targets for new antimicrobial agents. Bioorg. Med. Chem. 10, 855-867 (2002)

9 Dubrac, S., Bisicchia, P., Devine, K. M. \& Msadek, T. A matter of life and death: cell wall homeostasis and the WalKR (YycGF) essential signal transduction pathway. Mol. Microbiol. 70, 1307-1322 (2008)

10 Qin, Z. et al. Structure-based discovery of inhibitors of the YycG histidine kinase: new chemical leads to combat Staphylococcus epidermidis infections. BMC Microbiol. 6, 96 (2006).

11 Okada, A. et al. Targeting two-component signal transduction: a novel drug discovery system. Methods Enzymol. 422, 386-395 (2007). 
12 Watanabe, T. et al. Isolation and characterization of signermycin B, an antibiotic that targets the dimerization domain of histidine kinase WalK. Antimicrob. Agents Chemother. 56, 3657-3663 (2012).

13 Okada, A. et al. Walkmycin B targets WalK (YycG), a histidine kinase essential for bacterial cell growth. J. Antibiot. 63, 89-94 (2010).

14 Sawa, R. et al. Dioxamycin, a new benz[a]anthraquinone antibiotic. J. Antibiot. 44, 396-402 (1991).

15 Sezaki, M., Hara, T., Ayukawa, S., Takeuchi, T. \& Okami, Y. Studies on a new antibiotic pigment, aquayamycin. J. Antibiot. 21, 91-97 (1968).

$16 \mathrm{Liu}, \mathrm{W}$. C. et al. Isolation, characterization, and structure of rabelomycin, a new antibiotic. J. Antibiot. 23, 437-441 (1970),

17 Nagasawa, T., Fukao, H., Irie, H. \& Yamada, H. Sakyomicins A, B, C and D: new quinone-type antibiotics produced by a strain of Nocardia. Taxonomy, production, isolation and biological properties. J. Antibiot. 37, 693-699 (1984).
18 Edwards, M. J. et al. Crystal structure of the bifunctional antibiotic simocyclinone D8, bound to DNA gyrase. Science 326, 1415-1418 (2009).

19 Staneck, J. L. \& Roberts, G. D. Simplified approach to identification of aerobic actinomycetes by thin-layer chromatography. Appl. Microbiol. 28, 226-231 (1974).

20 Brosius, J., Palmer, M. L., Kennedy, P. J. \& Noller, H. F. Complete nucleotide sequence of a 16 S ribosomal RNA gene from Escherichia coli. Proc. Natl Acad. Sci. USA 75, 4801-4805 (1978).

21 Burla, M. C. et al. IL MILIONE: a suite of computer programs for crystal structure solution of proteins. J. Appl. Crystallogr. 40, 609-613 (2007).

22 Sheldrick, G. M. A short history of SHELX. Acta Crystallogr. A64, 112-122 (2008).

23 Clinical Laboratory Standards Institute. Method for Dilution Antimicrobial Susceptibility Test for Bacteria that Grow Aerobically; Approved Standard-Seventh Edition. M7-A7 (CLSI, Wayne, NJ, USA, 2006). 